\title{
The role of gut hormones in glucose homeostasis
}

\author{
Daniel J. Drucker ${ }^{1,2}$ \\ ${ }^{1}$ Banting and Best Diabetes Centre, University of Toronto, Toronto, Ontario, Canada. \\ 2Samuel Lunenfeld Research Institute, Department of Medicine, Mount Sinai Hospital, Toronto, Ontario, Canada.
}

\begin{abstract}
The gastrointestinal tract has a crucial role in the control of energy homeostasis through its role in the digestion, absorption, and assimilation of ingested nutrients. Furthermore, signals from the gastrointestinal tract are important regulators of gut motility and satiety, both of which have implications for the long-term control of body weight. Among the specialized cell types in the gastrointestinal mucosa, enteroendocrine cells have important roles in regulating energy intake and glucose homeostasis through their actions on peripheral target organs, including the endocrine pancreas. This article reviews the biological actions of gut hormones regulating glucose homeostasis, with an emphasis on mechanisms of action and the emerging therapeutic roles of gut hormones for the treatment of type 2 diabetes mellitus.
\end{abstract}

\section{Introduction}

After food ingestion, the digestion and absorption of nutrients is associated with increased secretion of multiple gut peptides that act on distant target sites to promote the efficient uptake and storage of energy. These peptide hormones are synthesized by specialized enteroendocrine cells located in the epithelium of the stomach, small bowel, and large bowel and are secreted at low basal levels in the fasting state. Plasma levels of most gut hormones rise briskly within minutes of nutrient intake and fall rapidly thereafter, mainly because they are cleared by the kidney and are enzymatically inactivated. Gut hormones activate neural circuits that communicate with peripheral organs, including the liver, muscle tissue, adipose tissue, and islets of Langerhans in the pancreas, to coordinate overall energy intake and assimilation (Figure 1). Incretin hormones (gastrointestinal hormones such as glucose-dependent insulinotropic polypeptide [GIP] and glucagon-like peptide-1 [GLP1] that cause an increase in the amount of insulin released from the $\beta$ cells of the islets) augment the magnitude of meal-stimulated insulin secretion from islet $\beta$ cells in a glucose-dependent manner (1). Incretin action facilitates the uptake of glucose by muscle tissue and the liver while simultaneously suppressing glucagon secretion by the $\alpha$ cells of the islets, leading to reduced endogenous production of glucose from hepatic sources.

More recent studies have defined roles for gut hormones in the control of $\beta$ cell growth and survival. Both GIP and GLP1 increase levels of cAMP, leading to expansion of $\beta$ cell mass and resistance to apoptosis in preclinical studies (2). Furthermore, the gut hormones cholecystokinin (CCK) and gastrin activate pathways that promote islet neogenesis and improve glucose homeostasis in experimental models of type 2 diabetes mellitus (T2DM). The pleiotropic actions of gut hormones converging on control of

Nonstandard abbreviations used: CCK, cholecystokinin; DPP4, dipeptidyl peptidase-4; GIP, glucose-dependent insulinotropic polypeptide; GIPR, GIP receptor; GLP, glucagon-like peptide; GLP1R, GLP1 receptor; HbA1c, hemoglobin A1c; PC1, prohormone convertase 1; PGDP, proglucagon-derived peptide; T1DM, type 1 diabetes mellitus; T2DM, type 2 diabetes mellitus; TCF7L2, transcription factor 7-like 2.

Conflict of interest: D.J. Drucker has served as an advisor or consultant within the past 12 months to Abbott Laboratories, Amgen Inc., Amylin Pharmaceuticals Inc., Arisaph Pharmaceuticals Inc., Bayer, Chugai Inc., ConjuChem Inc., Eli Lilly Inc., GlaxoSmithKline, Glenmark Pharmaceuticals, Johnson \& Johnson, Merck Research Laboratories, Novartis Pharmaceuticals, NPS Pharmaceuticals Inc., Phenomix Corp., Takeda, and Transition Therapeutics Inc. D.J. Drucker holds no stock in these companies. Citation for this article: J. Clin. Invest. 117:24-32 (2007). doi:10.1172/JCI30076. glucose homeostasis have fostered multiple efforts focused on mimicking gut hormone action for the treatment of T2DM, and several of these strategies, principally agonists of the GLP1 receptor (GLP1R) and inhibitors of the peptidase that enzymatically inactivates GIP and GLP1, dipeptidyl peptidase-4 (DPP4; also known as CD26), have recently been approved for the treatment of T2DM (3). Moreover, islet neogenesis therapy, using combinations of peptide hormones and EGF, is also in early clinical trials for the treatment of both type 1 diabetes mellitus (T1DM) and T2DM. This Review outlines our current understanding of the physiology and therapeutic potential of gut hormone action and highlights the emerging role of gut hormone-based approaches for the treatment of T2DM.

\section{Glucose-dependent insulinotropic polypeptide}

Although GIP was originally identified as a 42 -amino acid peptide that inhibited gastric motility in dogs, it was subsequently shown to potentiate glucose-stimulated insulin secretion $(4,5)$. GIP exerts its actions through the GIP receptor (GIPR), a member of the 7-transmembrane domain, heterotrimeric G protein-coupled glucagon receptor superfamily $(6,7)$. GIPR is widely expressed in the pancreas, stomach, small intestine, adipose tissue, adrenal cortex, lung, pituitary gland, heart, testis, vascular endothelium, bone, and brain $(6,8)$.

The sequence of GIP is highly conserved across species, with over $90 \%$ of the amino acid sequence being identical between human, rat, mouse, porcine, and bovine GIP. GIP is expressed predominantly in the stomach and the K cells of the proximal small intestine. GIP secretion is stimulated by nutrient ingestion and the rate of nutrient absorption; fat is a potent stimulus for GIP secretion in humans, whereas carbohydrates are more effective secretagogues in other species. GIP contains an alanine at position 2 and is a substrate for enzymatic inactivation by DPP4, an aminopeptidase that cleaves dipeptides from the amino terminus of proteins containing alanine or proline at position 2 (9). Therefore, the half-life of biologically active GIP is less than 2 minutes in rats $(10,11)$ and approximately 7 minutes and 5 minutes in healthy individuals and patients with T2DM, respectively (11). GIP is cleared through the kidney, and plasma levels of GIP are elevated in patients with uremia or chronic renal failure.

Biological actions of GIP. The dominant action of GIP is the stimulation of glucose-dependent insulin secretion (Table 1). This effect is mediated through elevation of intracellular cAMP 


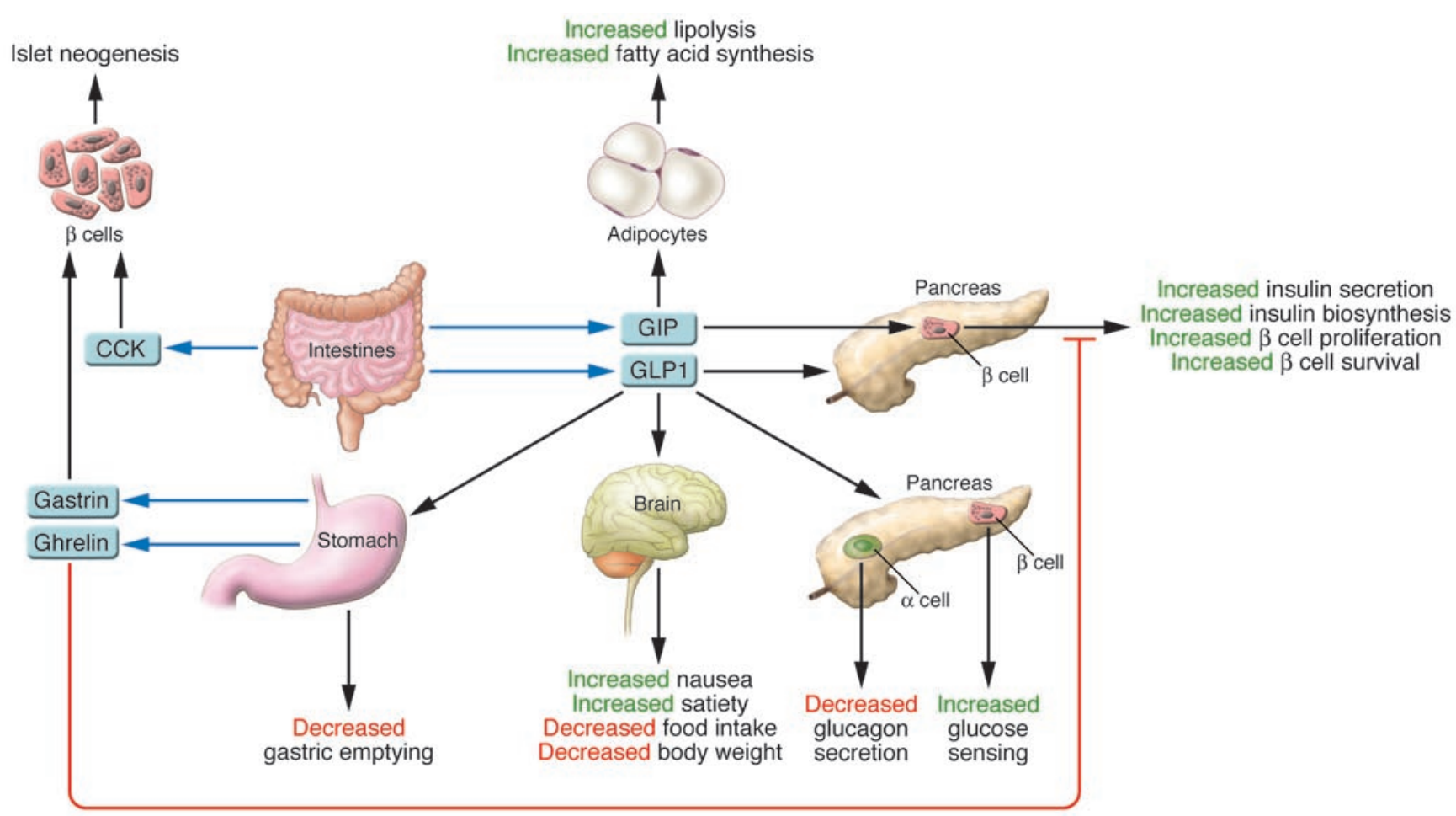

Figure 1

Actions of selected peptides on key tissues important for the control of glucose homeostasis. Both GLP1 and GIP promote insulin biosynthesis, insulin secretion, and islet $\beta$ cell survival. GLP1 exerts additional actions important for regulation of glucose homeostasis, including inhibition of glucagon secretion and gastric emptying, and induction of satiety. GIP, but not GLP1, directly engages receptors on adipocytes coupled to energy storage. In contrast, CCK and gastrin do not seem to acutely regulate levels of plasma glucose but might be important for stimulating the formation of new $\beta$ cells by stimulating islet neogenesis.

concentration and inhibition of ATP-sensitive $\mathrm{K}^{+}$channels, which together induces $\beta$ cell exocytosis (12). GIP also promotes insulin biosynthesis and exhibits growth factor-like activity for $\beta$ cells in vitro through activation of cAMP/protein kinase Adependent, MAPK-dependent, and PI3K-dependent pathways $(13,14)$. More recent data indicate that GIP also activates antiapoptotic pathways in a forkhead box O1-dependent (FOXO1dependent) manner in islet cells in vitro, and continuous GIP infusion enhances $\beta$ cell survival by reducing expression of the proapoptotic protein BAX and increasing expression of the antiapoptotic protein BCL2 in diabetic rodents in vivo (15).

The biological importance of endogenous GIP for the control of glucose homeostasis has been examined with the use of GIP antagonists, immunoneutralization of GIP activity, and GIPRdeficient mice. Diminution or elimination of GIP action using all 3 experimental approaches leads to defective insulin secretion after oral glucose administration (16-18), consistent with a role for GIP as an essential incretin hormone. An additional role for GIP, in the control of adipocyte biology, derives from findings that GIPR is expressed by adipocytes. Gipr ${ }^{-1-}$ mice have reduced fat depots, use fat as a preferred energy substrate, are resistant to diet-induced obesity, and have improved insulin sensitivity $(18,19)$. Furthermore, GIPR-deficient $o b / o b$ mice show reduced weight gain, improved glucose tolerance, and reduced adiposity relative to GIPR-sufficient $o b / o b$ mice (19). Complementary evidence of a role for GIP in adipocyte biology and insulin action arises from studies using GIPR antagonists (20). Daily administration of the GIPR antagonist Pro(3)GIP to $o b / o b$ mice reduced weight gain, improved fasting and postprandial glycemic excursion, and enhanced both insulin secretion and insulin sensitivity, independent of changes in food consumption and body weight. Hence GIP actions on the $\beta$ cell improve insulin secretion, whereas GIP promotes energy storage and reduces insulin action via effects on adipocytes. Therefore, it remains unclear whether activation or blockade of GIPR signaling would be an effective strategy for the treatment of T2DM.

GIP action in buman subjects. Circulating levels of basal and meal-stimulated GIP are normal in subjects with T2DM. But one should note that early studies of the circulating levels of GIP used assays that measured total immunoreactive GIP. However, as both GIP and GLP1 are rapidly degraded at the amino terminus, it is important to use amino-terminal-specific assays to discriminate between biologically active and amino-terminally degraded forms of GLP1 and GIP in the circulation. GIP is a potent incretin in normal humans, but the glucoregulatory actions of exogenous GIP are diminished in diabetic subjects $(21,22)$. Although the mechanisms underlying defective GIP action in experimental and clinical diabetes remain poorly understood, the $\beta$ cell GIPR undergoes rapid and reversible homologous desensitization in vitro (23), and defective GIP action in Zucker diabetic fatty rats has been correlated with reduced levels of Gipr mRNA in pancreatic islets (24). Whether intermittent bolus injections of GIP would be more effective at stimulating insulin secretion than continuous GIP infusion in patients with T2DM 
Table 1

Summary of GLP1 and GIP actions relevant to glucose control and the treatment of T2DM

\begin{tabular}{lcc}
\hline & GLP1 & GIP \\
Pancreas & & + \\
Stimulates glucose-dependent insulin secretion & + & + \\
Increases insulin gene transcription, mRNA stability, and biosynthesis & + & - \\
Inhibits glucagon secretion & + & - \\
Stimulates somatostatin secretion & + & + \\
Enhances $\beta$ cell response to glucose & + & + \\
Induces $\beta$ cell neogenesis and proliferation & + & + \\
Inhibits $\beta$ cell apoptosis & + & + \\
Increases expression of key genes important for differentiated $\beta$ cell function & & \\
Gastrointestinal tract & + \\
Inhibits gastric emptying & + \\
Inhibits gastric acid secretion & & + \\
Central nervous system & & \\
Inhibits food and water intake & + \\
Promotes satiety and weight loss & + \\
Enhances memory and neuronal survival & + \\
Activates aversive pathways leading to nausea/vomiting & + \\
Cardiovascular system & + \\
Improves cardiovascular function after ischemia & & - \\
Reduces the extent of cardiomyocyte death after experimental injury & & \\
Adipose tissue & & \\
Insulin-like lipogenic actions & & - \\
Lipid storage & + \\
\hline
\end{tabular}

"+" denotes that this action occurs; "-" denotes that this action does not occur. and increased levels of proglucagon mRNA in the remnant intestine $(29,30)$. PGDP secretion by enteroendocrine L cells is stimulated by neural signals, peptide hormones such as GIP (in rodents but not humans), and direct nutrient contact (31).

GLP1. GLP1 circulates as 2 equipotent forms, GLP1 $1_{7-37}$ and GLP1 $1_{7-36}$ amide (32-34), but most circulating GLP1 in humans is GLP1 $1_{7-36}$ amide (35). Plasma levels of full-length GLP1 are typically within the 5- to $10-\mathrm{pM}$ range in the fasting state and increase to approximately 50 pM after meal ingestion $(35,36)$. A small, but detectable, defect in meal-stimulated GLP1 secretion has been observed in subjects with obesity or T2DM about 60-120 minutes after food consumption (36). Clearance of GLP1 has received considerable attention because of the therapeutic potential of the peptide. The half-life of circulating native bioactive GLP1 is less than 2 minutes $(37,38)$, mostly because it is cleared by the kidney and degraded by DPP4.

is a subject of ongoing investigation (25). Similarly, the contribution of endogenous GIP to the therapeutic efficacy of DPP4 inhibitors remains uncertain. It remains possible that successful treatment of diabetes with DPP4 inhibitors or other therapeutic agents might be associated with partial or complete restoration of GIP responsivity, and hence there remains interest in the therapeutic potential of endogenous and exogenous GIP for the treatment of T2DM.

\section{The proglucagon-derived peptides}

Proglucagon-derived peptides (PGDPs) are generated by differential posttranslational processing of the precursor proglucagon in the pancreas, intestine, and brain. Although glucagon is the principal PGDP produced in $\alpha$ cells of the islets, prohormone convertase 1 (PC1) generates glicentin, oxyntomodulin, GLP1, and GLP2 from proglucagon in enteroendocrine L cells. The importance of PC1 processing of proglucagon in enteroendocrine L cells is illustrated by the phenotype of PC1-deficient mice, which exhibit multiple defects in prohormone processing, including a lack of substantial amounts of mature bioactive GLP1 and GLP2. Although most PGDP-expressing cells are located in the distal bowel and colon, there are also cells in the more proximal regions of the small bowel that produce both GLP1 and GIP.

Nutrient ingestion potently upregulates intestinal expression of the gene encoding proglucagon and the secretion of PGDPs, and a high-fiber diet (26), protein hydrolysates, and short-chain fatty acids increase levels of mRNA encoding proglucagon in enteroendocrine $\mathrm{L}$ cells $(27,28)$. Intestinal injury and resection are both associated with elevated circulating levels of PGDPs
GLP1 exerts multiple physiological actions leading to control of energy intake and nutrient assimilation (1) (Table 1). The original physiological role described for GLP1 was that of an incretin hormone that stimulates insulin secretion in a glucosedependent manner (39-41). GLP1 also increases transcription of the gene encoding insulin and enhances both the stability of the mRNA encoding insulin and biosynthesis of insulin by mechanisms that involve pathways that are both dependent on and independent of cAMP and protein kinase A, as well as pathways that increase the intracellular concentration of $\mathrm{Ca}^{2+}$ (Table 1). GLP1 also improves $\beta$ cell function by inducing increased expression of sulfonylurea receptor and inwardly rectifying $\mathrm{K}^{+}$channel (KIR6.2) in $\beta$ cells. It also prevents the downregulation of mRNA encoding KIR6.2 and the downregulation of ATP-sensitive $\mathrm{K}^{+}$ channel activity induced by high levels of glucose.

The physiological importance of endogenous GLP1 has been demonstrated using GLP1R antagonists, immunoneutralizing antisera, and Glp1r/- mice. Elimination of GLP1 activity with GLP1-immu-

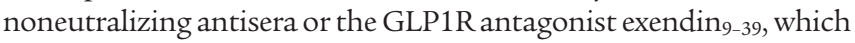
is a truncated form of the lizard GLP1-related peptide exendin-4, results in impaired glucose tolerance, and diminished glucose-stimulated insulin levels in both animals and humans (17, 42-44). Furthermore, basal GLP1 signaling in the fasting state is essential for regulation of glucose homeostasis, because infusion of exendin 9-39 increases levels of fasting glucose and glucagon in human subjects, demonstrating that even low basal levels of GLP1 exert a tonic inhibitory effect on glucagon-secreting $\alpha$ cells (45). Similarly, Glp1r/mice are glucose intolerant and have defective glucose-stimulated insulin secretion and fasting hyperglycemia (46). 
The insulinotropic and glucagonostatic effects of GLP1 depend on elevated levels of plasma glucose, thereby reducing the likelihood that treatment of diabetic subjects with GLP1R agonists would lead to hypoglycemia. In in vitro islet studies, GLP1 confers glucose sensitivity to $\beta$ cells and improves the number of $\beta$ cells able to respond to glucose. However, GLP1R signaling is not essential for $\beta$ cells to sense glucose in mouse islets (47). The demonstration that GLP1 upregulates molecular components of the glucose-sensing system in $\beta$ cells (that is, glucose transporters, ATP-sensitive $\mathrm{K}^{+}$channels, and glucokinase) might provide a partial mechanism for understanding the effects of GLP1 on the glucose responsiveness of $\beta$ cells $(48,49)$. Furthermore, short-term exposure to GLP1R agonists markedly improves glucose-stimulated insulin secretion in patients with T2DM (50-52).

GLP1 also promotes the proliferation and neogenesis of $\beta$ cells, reduces $\beta$ cell apoptosis, and increases differentiation of exocrine-like cells toward a more differentiated $\beta$ cell phenotype (2, 53-57). Conversely, elimination of mouse GLP1R signaling is associated with reduced numbers of large $\beta$ cell clusters and alterations in $\alpha$ cell topography (58). Furthermore, following partial pancreatectomy, Glp1 $r^{-/}$mice exhibit a reduced adaptive islet-regenerative response and greater hyperglycemia than littermate controls (59). Glp1 $r^{-/}$mice are also more sensitive to the cytotoxic and diabetogenic actions of streptozotocin (60). The signal transduction pathways whereby GLP1 mediates its proliferative effects have not been completely defined but involve PI3K, EGFR transactivation, and p38 MAPK and PKC $\zeta(61,62)$. Furthermore, GLP1 also activates a transcriptional program critical for cell survival; and pancreatic and duodenal homeobox gene 1 (PDX1), FOXO1, and insulin receptor substrate 2 (IRS2) have been identified as essential downstream targets for GLP1Rdependent cytoprotection in $\beta$ cells $(60,63,64)$. GLP1 also reduces the expression of proapoptotic genes, enhances glucosestimulated insulin secretion, and prevents apoptosis induced by high levels of glucose and/or palmitate in human $\beta$ cells through mechanisms involving AKT $(65,66)$.

Biological actions of glicentin, oxyntomodulin, and GLP2. Glicentin is a 69-amino acid PGDP that contains the 29-amino acid sequence of glucagon flanked by peptide extensions at both the amino and the carboxyl terminus. Although secreted together with GLP1 and GLP2 from enteroendocrine L cells, glicentin has not been shown to regulate glucose homeostasis. Oxyntomodulin also contains the 29-amino acid sequence of glucagon with an additional 8-amino acid carboxy-terminal extension. Oxyntomodulin stimulates intestinal glucose uptake (67) and insulin secretion (68) and inhibits gastric emptying, food intake, and meal-stimulated gastric acid secretion. Oxyntomodulin also induces satiety, inhibits food intake, and increases energy expenditure in humans $(69,70)$. Although oxyntomodulin is a weak agonist of both GLP1R and the glucagon receptor, the anorectic actions of oxyntomodulin are blocked by the GLP1R antagonist exendin $_{9-39}(71)$ and are eliminated in the absence of a functional GLP1R (72). Therefore, it seems that many of the pharmacological actions of oxyntomodulin represent heterologous activation of related PGDP receptors.

GLP2 is a 33-amino acid peptide secreted with GLP1 from enteroendocrine cells in a nutrient-dependent manner. GLP2 rapidly induces hexose transport in jejunal basolateral membrane vesicles (73). The main biological consequence of exogenous GLP2 administration is expansion of the mucosal epithelium in the small bowel. The intestinotrophic actions of GLP2 have been demonstrated in rodents with intestinal injury $(74,75)$ and in humans with short bowel syndrome (76-78). Although acute GLP2 administration increased levels of plasma glucagon, triglycerides, and FFAs in the postprandial state (79), there is no evidence that acute or chronic GLP2 administration directly regulates insulin secretion or glucose homeostasis in humans (76).

\section{GLP1R agonists and treatment of T2DM}

Native bioactive GLP1 rapidly lowers plasma glucose in patients with T2DM (80-82), and a 3-week trial of preprandial subcutaneous GLP1 injections improved postprandial glycemic control and reduced levels of glucagon in the plasma of subjects with T2DM (83). Furthermore, the improved $\beta$ cell function, and lowered fasting and postprandial glucose and hemoglobin A1c (HbA1c) levels observed after continuous subcutaneous GLP1 infusion for 6 weeks, were associated with modest weight loss and improved insulin sensitivity (50). The first GLP1R agonist approved for the treatment of T2DM was exendin-4, a naturally occurring GLP1-related peptide isolated from the venom of the lizard Heloderma suspectum (84). Exendin-4 exhibits 53\% amino acid identity to mammalian GLP1, is a potent GLP1R agonist (85), and is encoded by a gene distinct from that encoding lizard GLP1 (86). The actions of synthetic exendin-4 (exenatide) were examined in a series of phase III clinical trials in which exenatide was given twice daily to patients with T2DM who had not achieved satisfactory glucose control when taking metformin and/or a sulfonylurea. Exenatide therapy substantially lowered $\mathrm{HbA} 1 \mathrm{c}$ levels in all 3 treatment groups by about $0.9 \%(87-89)$, with $34 \%-46 \%$ of patients achieving a level of $\mathrm{HbA} 1 \mathrm{c}$ less than 7\% (87-89). The main side effect was nausea, although that diminished with ongoing therapy. However, patients receiving concomitant treatment with sulfonylureas also experienced increased rates of mild to moderate hypoglycemia. Importantly, exenatide therapy resulted in modest amounts of weight loss (87-89), with patients continuing on the drug for 82 weeks experiencing a mean weight loss of $4 \mathrm{~kg}(3)$. Although exendin-4-specific antibodies have been detected in $41 \%-49 \%$ of patients treated with exenatide (87-89), the antibodies do not correlate with the therapeutic response in most subjects (87-89).

Treatment with exenatide has also been compared with treatment with the insulin analogue insulin glargine as adjunctive therapy for patients with T2DM not optimally controlled by oral agents. Exenatide and insulin glargine produced comparable reductions in $\mathrm{HbA} 1 \mathrm{c}$ levels of approximately $1.1 \%$ after 26 weeks of therapy in patients with a mean initial HbA1c level of $8.2 \%-8.3 \%$ (90). The incidence of gastrointestinal side effects was substantially greater in patients treated with exenatide; however, exenatide therapy was associated with a mean weight loss of $2.3 \mathrm{~kg}$, whereas patients treated with insulin glargine gained approximately $1.8 \mathrm{~kg}$ (90). A combination of exenatide and thiazolidinedione therapy also seems to be effective in reducing HbA1c levels in the presence or absence of concomitant metformin therapy.

A number of GLP1R agonists are also in clinical development, including liraglutide, a DPP4-resistant analogue of GLP1 that binds noncovalently to albumin and is suitable for administration just once a day because it has a longer half-life than exenatide $(51,91)$. Liraglutide lowered HbA1c levels with no associated weight gain in a 12-week monotherapy study (92) and is currently in phase III clinical trials. A long-acting release (LAR) form of exenatide, designated exenatide LAR, is also under active inves- 
Table 2

Contrasting actions of GLP1R agonists and DPP4 inhibitors

\begin{tabular}{|c|c|c|}
\hline & $\begin{array}{c}\text { GLP1R } \\
\text { agonists }\end{array}$ & $\begin{array}{c}\text { DPP4 } \\
\text { inhibitors }\end{array}$ \\
\hline Administration & Injection & Orally available \\
\hline GLP1 concentrations & Pharmacological & Physiological \\
\hline Mechanisms of action & GLP1 & GLP1 plus GIP \\
\hline Activation of portal glucose sensor & No & Yes \\
\hline Increased insulin secretion & Yes & Yes \\
\hline Reduced glucagon secretion & Yes & Yes \\
\hline Gastric emptying & Inhibited & No effect \\
\hline Weight loss & Yes & No \\
\hline Expansion of $\beta$ cell mass (preclinical) & Yes & Yes \\
\hline Nausea and vomiting & Yes & No \\
\hline Potential immunogenicity & Yes & No \\
\hline
\end{tabular}

tigation (93). When administered once a week, it showed such promising efficacy in a pilot phase II clinical trial that it is currently being compared with twice-daily doses of exenatide in a phase III clinical trial of patients with T2DM. Taken together, the available evidence strongly suggests that additional long-acting GLP1R agonists with unique pharmacokinetic profiles will probably be approved for the treatment of T2DM.

\section{Inhibiting DPP4 to enhance levels of GLP1 and GIP}

DPP4 is widely expressed in many tissues and cell types and is catalytically active in both its cell-associated membrane-bound form and its soluble circulating form. DPP4 catalyzes the cleavage of GIP and GLP1 to bioinactive GIP $_{3-42}$ and GLP19-37 or GLP19-36 amide, respectively. The importance of DPP4 for glucose homeostasis is revealed in studies characterizing the phenotype of DPP4-deficient rodents. DPP4-deficient rats exhibit elevated levels of GLP1 and improved glucose tolerance (94), and DPP4deficient mice exhibit increased levels of plasma GLP1 and GIP (95), enhanced insulin secretion, improved glucose tolerance, and resistance to diet-induced obesity.

Consistent with the observations in rodents lacking DPP4, DPP4 inhibitors lower blood glucose, stimulate insulin secretion, and increase the levels of intact GLP1 and GIP in preclinical models of diabetes $(96,97)$. Similarly, DPP4 inhibitors produce substantial reduction of glycemia as well as decreased levels of circulating glucagon and improvement in the insulin/glucose ratio in humans with T2DM $(98,99)$. Two DPP4 inhibitors, vildagliptin and sitagliptin, have completed phase III clinical trials, and their efficacy in both monotherapy and combination therapy regimens was examined. Both vildagliptin and sitagliptin markedly lower $\mathrm{HbA1c}$ when used either as initial monotherapy, or in combination with other oral antidiabetic agents such as biguanides, thiazolidinediones, or sulfonylureas. The results of these phase III clinical trials are now under regulatory review, and the first DPP4 inhibitor (sitagliptin) was approved for the treatment of T2DM in the United States in October 2006. The contrasting actions of GLP1R agonists and DPP4 inhibitors are summarized in Table 2. Although both types of agent stimulate insulin and inhibit glucagon secretion, GLP1R agonists, but not DPP4 inhibitors, inhibit gastric emptying and promote satiety, leading to weight loss. In contrast, DPP4 inhibitors seem to be extremely well tolerated without substantial nausea or vomiting.

\section{Other gut hormones that can impact glucose homeostasis}

In addition to the well-known roles of incretin hormones in the control of glucose homeostasis, several gut hormones produced in the stomach (ghrelin and gastrin) and small and large bowel (cholecystokinin [CCK]) exhibit actions important for glucoregulation and the treatment of T2DM.

CCK and gastrin. Although the classical actions of CCK and gastrin are focused on the control of gallbladder contraction, satiety, and pancreatic and gastric acid secretion, both peptides exert actions relevant to the control of glucose homeostasis. CCK has 2 main receptors, CCKAR (also known as CCK1R) and CCKBR (also known as CCK2R), and it is CCKBR that mediates the effects of CCK on the control of glucose homeostasis by the pancreas. Both gastrin and CCK have been shown to stimulate glucagon release from human islets in vitro. However, CCK also stimulates insulin secretion in rodents in a glucose-dependent manner, and infusion of a form of CCK containing 8 amino acids (CCK-8) increases plasma insulin concentration and reduces glucose excursion following meal ingestion in normal and T2DM subjects (100). Although glucose homeostasis seems normal in mice with an inactivating mutation in either the gene encoding CCKAR or the gene encoding CCKBR, gastrin-deficient mice exhibit mild hypoglycemia and a defective glucagon-secretory response to insulin-induced hypoglycemia (101). Both CCK and gastrin also exert proliferative effects on pancreatic $\beta$ cells. CCK- 8 promotes regeneration of $\beta$ cells in rats after nicotinamide- and streptozotocin-induced $\beta$ cell destruction (102), and gastrin promotes islet neogenesis in transdifferentiated pancreatic tissue in vivo (103). Furthermore, a combination of EGF and gastrin induces islet neogenesis in mice after alloxan-induced $\beta$ cell destruction (104), and in NOD mice with experimental autoimmune diabetes (105). Of potential clinical relevance, the combination of EGF and gastrin promotes the formation of new $\beta$ cells from pancreatic ductal epithelium in vitro and increases the number of functioning $\beta$ cells after transplantation of human islets into NOD×SCID mice (106). Furthermore, genetic disruption of the gene encoding CCK markedly increases the severity of diabetes in $o b / o b$ mice. Hence there is ongoing interest in the use of a combination of EGF and gastrin for regeneration of $\beta$ cell mass, a concept that is currently being tested in human clinical trials in subjects with either T1DM or T2DM.

Ghrelin. Ghrelin is a 28 -amino acid orexigenic hormone secreted from the stomach in the fasting state whose actions promote food consumption in rodent and human studies (107). Ghrelin also seems to have both physiological and pharmacological actions on the endocrine pancreas. Acylated bioactive ghrelin is produced in the recently described $\varepsilon$ cell in the pancreatic islets (108), potentially providing a local source of ghrelin that acts on $\beta$ cells of the islets. Blocking the function of endogenous ghrelin with the use of an antagonist for its receptor (the growth hormone secretagogue receptor) markedly lowered fasting glucose concentrations, attenuated glycemic excursion, and enhanced insulin responses during a glucose tolerance test, suggesting an inhibitory role for ghrelin in the control of insulin secretion (109). Conversely, exogenous ghrelin increased glycemic excursion and reduced insulin secretion in rodents in vivo, and ghrelin seems to directly inhibit insulin secretion in isolated islets in vitro (109). Similar differences in the function of endogenous and exogenous ghrelin have been observed in other studies. For 
example, the physiological importance of endogenous ghrelin as an inhibitor of insulin secretion was illustrated by the observation that ghrelin-deficient $o b / o b$ mice expressed lower amounts of uncoupling protein 2 in their islets, secreted more insulin, and were more sensitive to insulin than ghrelin-sufficient $o b / o b$ mice (110). Conversely, central administration of ghrelin increases the rate at which white and brown adipose tissue, but not skeletal muscle, uses glucose (111). Intriguingly, ghrelin treatment of neonatal rats exposed to streptozotocin attenuated the development of diabetes and was associated with increased islet neogenesis, suggesting that ghrelin might have a proliferative or cytoprotective effect on $\beta$ cells (112). Taken together, the available evidence suggests an emerging role for ghrelin in the central (body weight) and peripheral ( $\beta$ cell function) control of glucose homeostasis.

\section{Gastrointestinal disorders affecting glucose homeostasis}

Intestinal injury and inflammation. Enteroendocrine cell biology is often perturbed in the setting of intestinal injury; however, there is limited information about changes in the actions of gut peptides in patients with intestinal disease. Although reduction of enteroendocrine cell mass and reduced secretion of insulinotropic peptides might theoretically increase the risk of glucose intolerance, intestinal disorders are often accompanied by loss of nutrient-absorptive capacity, diarrhea, anorexia, and weight loss, which offset the clinical impact of incretin deficiency. However, plasma levels of several gut peptides can be elevated in response to different forms of intestinal inflammation and gut resection (113-115). Patients with extensive resection of the small and large bowel exhibit substantial reductions in circulating levels of GLP2 after meal ingestion, whereas preservation of the colon seems to be important for maintaining levels of both GLP1 and GLP2 in adult human subjects. In contrast, the colon seems to be less important for preservation of plasma levels of GLP2 in infants with nutrient malabsorption consequent to intestinal surgery.

Alteration of the normal anatomy of the gastrointestinal tract, as occurs following gastric bypass surgery, can be associated with dysregulated gut hormone secretion. Plasma levels of GLP1 and GIP are elevated in some patients after gastric bypass; this perhaps contributes, together with weight loss and enhanced insulin sensitivity, to the improved glucose tolerance observed in subsets of these patients (116). Similarly, postprandial elevations in levels of the anorectic peptide, peptide YY, and GLP1 have been described in patients after Roux-en-Y gastric bypass surgery, and this was associated with enhanced satiety, weight loss, and improved glucose homeostasis $(117,118)$. A syndrome of postprandial hyperinsulinemic hypoglycemia associated with pancreatic nesidioblastosis has been described in several patients after gastric bypass $(119,120)$, and some of these patients have markedly increased levels of plasma GLP1 in the postprandial state (119). Although patients with postprandial hyperinsulinemic hypoglycemia probably present with combined abnormalities in the control of gastric emptying and an acquired defect in $\beta$ cell function manifesting as postprandial hypoglycemia, it remains less clear whether this syndrome is causally related to changes in levels of gut hormones, and it remains uncertain whether there are true changes in $\beta$ cell mass or nesidioblastosis in affected subjects (121).
Genetic disorders. An inactivating mutation in the gene encoding PC1 has been described in several subjects (122). Although loss of PC1 action might be predicted to include relative deficiency of bioactive GIP and GLP1, the glucose intolerance, intractable diarrhea, and malabsorption phenotype in these individuals probably obscures the potential importance of loss of incretin action in this setting. Similarly, although inactivating mutations in the gene encoding the transcription factor neurogenin-3 cause profound loss of gut endocrine cell populations in the small intestine, severe chronic malabsorptive diarrhea was the clinical presentation in all 3 affected humans (123).

In contrast, specific genetic polymorphisms in the gene encoding transcription factor 7-like 2 (TCF7L2) are associated with an increased risk of developing T2DM in 3 independent populations (124). Furthermore, inheriting 2 specific TCF7L2 variants, rs12255372 and rs7903146, has been associated with a relative reduction in insulin secretion and an increased likelihood of progression from impaired glucose tolerance to T2DM in the Diabetes Prevention Program study (125). Although the precise mechanisms linking TCF7L2 to control of $\beta$ cell function and glucose homeostasis remain unclear, this transcription factor seems to be important for control of proglucagon gene expression, and therefore GLP1 production, in gut endocrine cells. Therefore, examination of whether reduced levels of meal-stimulated GLP1 responses contribute an increased risk for the development of T2DM in subjects with different TCF7L2 genotypes seems logical.

\section{Summary and future directions}

The diverse actions of gut peptides in regulating the control of satiety, gut motility, nutrient digestion and absorption, and disposal and storage of energy have focused increasing interest on the therapeutic potential of these hormones for the treatment of disorders of energy homeostasis. Considerable evidence supports an essential biological role for endogenous GLP1 in the control of $\beta$ cell function, and clinical data demonstrating the efficacy of the first GLP1R agonist, exenatide, are compelling. Notably, most antidiabetic agents are often associated with weight gain over time, whereas exenatide therapy is frequently associated with weight loss, an important clinical feature that differentiates GLP1R agonists from all other available therapies for T2DM. The introduction of DPP4 inhibitors in the clinic will provide an opportunity to enhance incretin action by single daily administration of a well-tolerated orally available tablet, a feature appealing to both physicians and many patients who might be reluctant to initiate injectable therapies. Furthermore, there remains great interest in understanding whether 1 or more gut hormones might be useful for $\beta$ cell protection and/or regeneration of new $\beta$ cells for the treatment of T1DM, and clinical trials using islet neogenesis therapy (in the form of a combination of gastrin and EGF) might soon provide answers to these questions. Moreover, GLP2 is being investigated for its ability to restore nutrient absorption and reduce mucosal damage in the setting of short bowel syndrome and Crohn disease and might soon represent the first reparative therapy available for patients with intestinal injury. As most of these hormones are secreted transiently after nutrient ingestion and then rapidly inactivated and cleared, there has been considerable interest in the development of degradation-resistant peptide hormone agonists for the treatment of human disorders. Given the actions of these gut peptides on cell proliferation and survival, and the inherent 
potential immunogenicity of modified gut peptides, the enthusiasm for the use of these new agents should be combined with ongoing vigilance for potential adverse events as we begin to use these new agents for the treatment of human disease.

\section{Acknowledgments}

D.J. Drucker is supported in part by a Canada Research Chair in Regulatory Peptides and by operating grants from the Juvenile Diabetes
Research Foundation, the Canadian Institutes of Health Research, the Canadian Diabetes Association, the National Cancer Institute of Canada, and the McLaughlin Center for Molecular Medicine.

Address correspondence to: Daniel J. Drucker, Samuel Lunenfeld Research Institute, Mount Sinai Hospital, 600 University Avenue, Toronto, Ontario M5G 1X5, Canada. Phone: (416) 361-2661; Fax: (416) 361-2669; E-mail: d.drucker@utoronto.ca.
1. Drucker, D.J. 2006. The biology of incretin hormones. Cell Metab. 3:153-165.

2. Drucker,D.J.2003. Glucagon-like peptides: regulators of cell proliferation, differentiation, and apoptosis. Mol. Endocrinol. 17:161-171.

3. Riddle, M.C., and Drucker, D.J. 2006. Emerging therapies mimicking the effects of amylin and glucagon-like peptide 1. Diabetes Care. 29:435-449.

4. Dupre, J., Ross, S.A., Watson, D., and Brown, J.C. 1973. Stimulation of insulin secretion by gastric inhibitory polypeptide in man. J. Clin. Endocrinol. Metab. 37:826-828.

5. Pederson, R.A., Schubert, H.E., and Brown, J.C. 1975. Gastric inhibitory polypeptide. Its physiologic release and insulinotropic action in the dog. Diabetes. 24:1050-1056.

6. Usdin, T.B., Mezey, E., Button, D.C., Brownstein, M.J., and Bonner, T.I. 1993. Gastric inhibitory polypeptide receptor, a member of the secretin-vasoactive intestinal peptide receptor family, is widely distributed in peripheral organs and the brain. Endocrinology. 133:2861-2870.

7. Mayo, K.E., et al. 2003. International Union of Pharmacology. XXXV. The glucagon receptor family. Pharmacol. Rev. 55:167-194.

8. Yip, R.G., Boylan, M.O., Kieffer, T.J., and Wolfe, M.M. 1998. Functional GIP receptors are present on adipocytes. Endocrinology. 139:4004-4007.

9. Mentlein, R., Gallwitz, B., and Schmidt, W.E. 1993. Dipeptidyl-peptidase IV hydrolyses gastric inhibitory polypeptide, glucagon-like peptide1(7-36)amide, peptide histidine methionine and is responsible for their degradation in human serum. Eur. J. Biochem. 214:829-835.

10. Kieffer, T.J., McIntosh, C.H., and Pederson, R.A. 1995. Degradation of glucose-dependent insulinotropic polypeptide and truncated glucagon-like peptide 1 in vitro and in vivo by dipeptidyl peptidase IV. Endocrinology. 136:3585-3596.

11. Deacon, C.F., Nauck, M.A., Meier, J., Hucking, K., and Holst, J.J. 2000. Degradation of endogenous and exogenous gastric inhibitory polypeptide in healthy and in type 2 diabetic subjects as revealed using a new assay for the intact peptide. J. Clin. Endocrinol. Metab. 85:3575-3581.

12. Gromada, J., et al. 1998. Glucagon-like peptide 1 (7-36) amide stimulates exocytosis in human pancreatic beta-cells by both proximal and distal regulatory steps in stimulus-secretion coupling. Diabetes. 47:57-65.

13. Trumper,A., et al. 2001. Glucose-dependent insulinotropic polypeptide is a growth factor for beta (INS-1) cells by pleiotropic signaling. Mol. Endocrinol. 15:1559-1570

14. Trumper, A., Trumper, K., and Horsch, D. 2002. Mechanisms of mitogenic and anti-apoptotic signaling by glucose-dependent insulinotropic polypeptide in beta(INS-1)-cells. J. Endocrinol. 174:233-246.

15. Kim, S.J., et al. 2005. GIP stimulation of pancreatic beta-cell survival is dependent upon phosphatidylinositol 3-kinase (PI3-K)/protein kinase B (PKB) signaling, inactivation of the forkhead transcription factor Foxo1 and downregulation of bax expression. J. Biol. Chem. 280:22297-22307.

16. Tseng, C.C., Kieffer, T.J., Jarboe, L.A., Usdin, T.B., and Wolfe, M.M. 1996. Postprandial stimulation of insulin release by glucose-dependent insulinotro- pic polypeptide (GIP). Effect of a specific glucosedependent insulinotropic polypeptide receptor antagonist in the rat. J. Clin. Invest. 98:2440-2445.

17. Baggio, L., Kieffer, T.J., and Drucker, D.J. 2000. Glucagon-like peptide-1, but not glucose-dependent insulinotropic peptide, regulates fasting glycemia and nonenteral glucose clearance in mice. Endocrinology. 141:3703-3709.

18. Miyawaki, K., et al. 1999. Glucose intolerance caused by a defect in the entero-insular axis: a study in gastric inhibitory polypeptide receptor knockout mice. Proc. Natl. Acad. Sci. U. S. A. 96:14843-14847.

19. Miyawaki, K., et al. 2002. Inhibition of gastric inhibitory polypeptide signaling prevents obesity. Nat. Med. 8:738-742.

20. Gault, V.A., et al. 2005. Chemical ablation of gastric inhibitory polypeptide receptor action by daily (Pro3)GIP administration improves glucose tolerance and ameliorates insulin resistance and abnormalities of islet structure in obesity-related diabetes. Diabetes. 54:2436-2446.

21. Nauck, M.A., et al. 1993. Preserved incretin activity of glucagon-like peptide 1 [7-36 amide] but not of synthetic human gastric inhibitory polypeptide in patients with type-2 diabetes mellitus. J. Clin. Invest. 91:301-307.

22. Elahi, D., et al. 1994. The insulinotropic actions of glucose-dependent insulinotropic polypeptide (GIP) and glucagon-like peptide-1 (7-37) in normal and diabetic subjects. Regul. Pept. 51:63-74.

23. Fehmann, H.-C., Goke, R., and Goke, B. 1995. Cell and molecular biology of the incretin hormones glucagon-like peptide 1 and glucose-dependent releasing polypeptide. Endocr. Rev. 16:390-410.

24. Lynn, F.C., et al. 2001. Defective glucose-dependent insulinotropic polypeptide receptor expression in diabetic fatty Zucker rats. Diabetes. 50:1004-1011.

25. Meier, J.J., et al. 2004. Stimulation of insulin secretion by intravenous bolus injection and continuous infusion of gastric inhibitory polypeptide in patients with type 2 diabetes and healthy control subjects. Diabetes. 53(Suppl. 3):S220-S224.

26. Reimer, R.A., and McBurney, M.I. 1996. Dietary fiber modulates intestinal proglucagon messenger ribonucleic acid and postprandial secretion of glucagon-like peptide-1 and insulin in rats. Endocrinology. 137:3948-3956.

27. Tappenden, K.A., Thomson, A.B., Wild, G.E., and McBurney, M.I. 1996. Short-chain fatty acids increase proglucagon and ornithine decarboxylase messenger RNAs after intestinal resection in rats. JPEN J. Parenter. Enteral Nutr. 20:357-362.

28. Tappenden, K.A., and McBurney, M.I. 1998. Systemic short-chain fatty acids rapidly alter gastrointestinal structure, function, and expression of early response genes. Dig. Dis. Sci. 43:1526-1536.

29. Ulshen, M.H., et al. 1996. Increased ileal proglucagon expression after jejunectomy is not suppressed by inhibition of bowel growth. Dig. Dis. Sci. 41:677-683.

30. Taylor, R.G., Beveridge, D.J., and Fuller, P.J. 1992. Expression of ileal glucagon and peptide tyrosinetyrosine genes. Response to inhibition of polyamine synthesis in the presence of massive smallbowel resection. Biochem. J. 286:737-741.

31. Brubaker, P.L., and Anini, Y. 2003. Direct and indirect mechanisms regulating secretion of glucagonlike peptide- 1 and glucagon-like peptide-2. Can. J.
Physiol. Pharmacol. 81:1005-1012.

32. Mojsov, S., Kopczynski, M.G., and Habener, J.F. 1990. Both amidated and nonamidated forms of glucagonlike peptide I are synthesized in the rat intestine and the pancreas. J. Biol. Chem. 265:8001-8008.

33. Orskov, C., Wettergren, A., and Holst, J.J. 1993. Biological effects and metabolic rates of glucagonlike peptide-1 7-36 amide and glucagonlike peptide-1 7-37 in healthy subjects are indistinguishable. Diabetes. 42:658-661.

34. Wettergren, A., Pridal, L., Wojdemann, M., and Holst, J.J. 1998. Amidated and non-amidated glucagon-like peptide-1 (GLP-1): non-pancreatic effects (cephalic phase acid secretion) and stability in plasma in humans. Regul. Pept. 77:83-87.

35. Orskov, C., Rabenhoj, L., Wettergren, A., Kofod, H., and Holst, J.J. 1994. Tissue and plasma concentrations of amidated and glycine-extended glucagonlike peptide I in humans. Diabetes. 43:535-539.

36. Vilsboll, T., Krarup, T., Deacon, C.F., Madsbad, S., and Holst, J.J. 2001. Reduced postprandial concentrations of intact biologically active glucagonlike peptide 1 in type 2 diabetic patients. Diabetes. 50:609-613.

37. Hansen, L., Deacon, C.F., Orskov, C., and Holst, J.J. 1999. Glucagon-like peptide-1-(7-36)amide is transformed to glucagon-like peptide-1-(936)amide by dipeptidyl peptidase IV in the capillaries supplying the L cells of the porcine intestine. Endocrinology. 140:5356-5363.

38. Deacon, C.F., et al. 1995. Both subcutaneously and intravenously administered glucagon-like peptide 1 are rapidly degraded from the $\mathrm{NH} 2$-terminus in type II diabetic patients and in healthy subjects. Diabetes. 44:1126-1131.

39. Kreymann, B., Williams, G., Ghatei, M.A., and Bloom, S.R. 1987. Glucagon-like peptide-1 7-36: a physiological incretin in man. Lancet. 2:1300-1304. 40. Mojsov, S., Weir, G.C., and Habener, J.F. 1987. Insulinotropin: glucagon-like peptide I (7-37) coencoded in the glucagon gene is a potent stimulator of insulin release in the perfused rat pancreas. J. Clin. Invest. 79:616-619.

41. Orskov, C., Holst, J.J., and Nielsen, O.V. 1988. Effect of truncated glucagon-like peptide- 1 [proglucagon-(78-107) amide] on endocrine secretion from pig pancreas, antrum, and nonantral stomach. Endocrinology. 123:2009-2013.

42. D'alessio, D.A., et al. 1996. Elimination of the action of glucagon-like peptide 1 causes an impairment of glucose tolerance after nutrient ingestion by healthy baboons. J. Clin. Invest. 97:133-138.

43. Edwards, C.M., et al. 1999. Glucagon-like peptide 1 has a physiological role in the control of postprandial glucose in humans: studies with the antagonist exendin 9-39. Diabetes. 48:86-93.

44. Wang, Z., et al. 1995. Glucagon-like peptide 1 is a physiological incretin in rat. J. Clin. Invest. 95:417-421.

45. Schirra, J., et al. 1998. Exendin(9-39)amide is an antagonist of glucagon-like peptide-1(7-36)amide in humans. J. Clin. Invest. 101:1421-1430.

46. Scrocchi, L.A., et al. 1996. Glucose intolerance but normal satiety in mice with a null mutation in the glucagon-like peptide receptor gene. Nat. Med. 2:1254-1258.

47. Flamez, D., et al. 1998. Mouse pancreatic beta cells 
exhibit preserved glucose competence after disruption of the glucagon-like peptide 1 receptor gene. Diabetes. 47:646-652.

48. Wang, Y.H., et al. 1995. Glucagon-like peptide-1 affects gene transcription and messenger ribonucleic acid stability of components of the insulin secretory system in RIN 1046-38 cells. Endocrinology. 136:4910-4917.

49. Wang, Y., et al. 1997. Glucagon-like peptide-1 can reverse the age-related decline in glucose tolerance in rats. J. Clin. Invest. 99:2883-2889.

50. Zander, M., Madsbad, S., Madsen, J.L., and Holst, J.J. 2002. Effect of 6-week course of glucagon-like peptide 1 on glycaemic control, insulin sensitivity, and beta-cell function in type 2 diabetes: a parallelgroup study. Lancet. 359:824-830.

51. Degn, K.B., et al. 2004. One week's treatment with the long-acting glucagon-like peptide 1 derivative liraglutide (NN2211) markedly improves 24-h glycemia and alpha- and beta-cell function and reduces endogenous glucose release in patients with type 2 diabetes. Diabetes. 53:1187-1194.

52. Fehse, F., et al. 2005. Exenatide augments first- and second-phase insulin secretion in response to intravenous glucose in subjects with type 2 diabetes. J. Clin. Endocrinol. Metab. 90:5991-5997.

53. Xu, G., Stoffers, D.A., Habener, J.F., and BonnerWeir, S. 1999. Exendin-4 stimulates both beta-cell replication and neogenesis, resulting in increased beta-cell mass and improved glucose tolerance in diabetic rats. Diabetes. 48:2270-2276.

54. Edvell, A., and Lindstrom, P. 1999. Initiation of increased pancreatic islet growth in young normoglycemic mice (Umea +/?). Endocrinology. 140:778-783.

55. Stoffers, D.A., et al. 2000. Insulinotropic glucagon-like peptide-1 agonists stimulate expression of homeodomain protein IDX-1 and increase islet size in mouse pancreas. Diabetes. 49:741-748.

56. Perfetti, R., Zhou, J., Doyle, M.E., and Egan, J.M. 2000. Glucagon-like peptide-1 induces cell proliferation and pancreatic-duodenum homeobox-1 expression and increases endocrine cell mass in the pancreas of old, glucose-intolerant rats. Endocrinology. 141:4600-4605.

57. Kim, J.G., et al. 2003. Development and characterization of a glucagon-like peptide 1-albumin conjugate: the ability to activate the glucagon-like peptide 1 receptor in vivo. Diabetes. 52:751-759.

58. Ling, Z., et al. 2001. Glucagon-like peptide 1 receptor signaling influences topography of islet cells in mice. Virchows Arch. 438:382-387.

59. De Leon, D.D., et al. 2003. Role of endogenous glucagon-like peptide- 1 in islet regeneration following partial pancreatectomy. Diabetes. 5252:365-371.

60. Li, Y., et al. 2003. Glucagon-like peptide-1 receptor signaling modulates beta cell apoptosis. J. Biol. Chem. 278:471-478

61. Buteau, J., et al. 2001. Protein kinase Czeta activation mediates glucagon-like peptide-1-induced pancreatic beta-cell proliferation. Diabetes. 50:2237-2243.

62. Brubaker, P.L., and Drucker, D.J. 2004. Glucagonlike peptides regulate cell proliferation and apoptosis in the pancreas, gut and central nervous system. Endocrinology. 145:2653-2659.

63. Park, S., et al. 2005. Exendin-4 uses Irs 2 signaling to mediate pancreatic beta cell growth and function. J. Biol. Chem. 281:1159-1168.

64. Buteau, J., Spatz, M.L., and Accili, D. 2006. Transcription factor FoxO1 mediates glucagon-like peptide-1 effects on pancreatic beta-cell mass. Diabetes. 55:1190-1196.

65. Farilla, L., et al. 2003. Glucagon-like peptide 1 inhibits cell apoptosis and improves glucose responsiveness of freshly isolated human islets. Endocrinology. 144:5149-5158.

66. Buteau, J., et al. 2004. Glucagon-like peptide-1 prevents beta cell glucolipotoxicity. Diabetologia. 47:806-815.
67. Collie, N.L., Zhu, Z., Jordan, S., and Reeve, J.R., Jr. 1997. Oxyntomodulin stimulates intestinal glucose uptake in rats. Gastroenterology. 112:1961-1970.

68. Jarrousse, C., Bataille, D., and Jeanrenaud, B. 1984. A pure enteroglucagon, oxyntomodulin (glucagon 37), stimulates insulin release in perfused rat pancreas. Endocrinology. 115:102-105.

69. Wynne, K., et al. 2007. Oxyntomodulin increases energy expenditure in addition to decreasing energy intake in overweight and obese humans: a randomised controlled trial. Int. J. Obes. (Lond.) In press.

70. Wynne, K., et al. 2005. Subcutaneous oxyntomodulin reduces body weight in overweight and obese subjects: a double-blind, randomized, controlled trial. Diabetes. 54:2390-2395.

71. Dakin, C.L., et al. 2001. Oxyntomodulin inhibits food intake in the rat. Endocrinology. 142:4244-4250.

72. Baggio, L.L., Huang, Q., Brown, T.J., and Drucker, D.J. 2004. Oxyntomodulin and glucagon-like peptide-1 differentially regulate murine food intake and energy expenditure. Gastroenterology. 127:546-558.

73. Cheeseman, C.I., and Tsang, R. 1996. The effect of gastric inhibitory polypeptide and glucagon like peptides on intestinal hexose transport. Am.J. Physiol. Gastrointest. Liver Physiol. 271:G477-G482.

74. Boushey, R.P., Yusta, B., and Drucker, D.J. 1999. Glucagon-like peptide 2 decreases mortality and reduces the severity of indomethacin-induced murine enteritis. Am. J. Physiol. 277:E937-E947.

75. Boushey, R.P., Yusta, B., and Drucker, D.J. 2001. Glucagon-like peptide (GLP)-2 reduces chemotherapy-associated mortality and enhances cell survival in cells expressing a transfected GLP-2 receptor. Cancer Res. 61:687-693.

76. Jeppesen, P.B., et al. 2001. Glucagon-like peptide 2 improves nutrient absorption and nutritional status in short-bowel patients with no colon. Gastroen terology. 120:806-815.

77. Jeppesen, P.B. 2003. Clinical significance of GLP-2 in short-bowel syndrome. J. Nutr. 133:3721-3724.

78. Jeppesen, P.B., et al. 2005. Teduglutide (ALX-0600), a dipeptidyl peptidase IV resistant glucagon-like peptide 2 analogue, improves intestinal function in short bowel syndrome patients. Gut. 54:1224-1231.

79. Meier, J.J., et al. 2006. Glucagon-like peptide 2 stimulates glucagon secretion, enhances lipid absorption, and inhibits gastric acid secretion in humans. Gastroenterology. 130:44-54

80. Gutniak, M., Orskov, C., Holst, J.J., Ahren, B., and Efendic, S. 1992. Antidiabetogenic effect of glucagon-like peptide-1 (7-36)amide in normal subjects and patients with diabetes mellitus. N. Engl. J. Med. 326:1316-1322.

81. Rachman, J., et al. 1996. Normalization of insulin responses to glucose by overnight infusion of glucagon-like peptide 1(7-36)amide in patients with NIDDM. Diabetes. 45:1524-1530.

82. Rachman, J., Barrow, B.A., Levy, J.C., and Turner, R.C. 1997. Near normalization of diurnal glucose concentrations by continuous administration of glucagon-like peptide 1 (GLP-1) in subjects with NIDDM. Diabetologia. 40:205-211.

83. Todd, J.F., Wilding, J.P., Edwards, C.M., Ghatei, M.A., and Bloom, S.R. 1997. Glucagon-like peptide-1(GLP-1): a trial of treatment in non-insulin-dependent diabetes mellitus. Eur. J. Clin. Invest. 27:533-536.

84. Eng, J., Kleinman, W.A., Singh, L., Singh, G., and Raufman, J.P. 1992. Isolation and characterization of exendin 4, an exendin 3 analogue from Heloderma suspectum venom. J. Biol. Chem. 267:7402-7405.

85. Goke, R., et al. 1993. Exendin-4 is a high potency agonist and truncated exendin-(9-39)-amide an antagonist at the glucagon-like peptide 1-(7-36)amide receptor of insulin-secreting $\beta$-cells. J. Biol. Chem. 268:19650-19655.

86. Chen, Y.E., and Drucker, D.J. 1997. Tissue-specific expression of unique mRNAs that encode proglucagon-derived peptides or exendin 4 in the lizard.
J. Biol. Chem. 272:4108-4115.

87. Buse,J.B., et al. 2004. Effects of exenatide (Exendin-4) on glycemic control over 30 weeks in sulfonylureatreated patients with type 2 diabetes. Diabetes Care. 27:2628-2635.

88. DeFronzo, R.A., et al. 2005. Effects of exenatide (exendin-4) on glycemic control and weight over 30 weeks in metformin-treated patients with type 2 diabetes. Diabetes Care. 28:1092-1100.

89. Kendall, D.M., et al. 2005. Effects of exenatide (exendin-4) on glycemic control over 30 weeks in patients with type 2 diabetes treated with metformin and a sulfonylurea. Diabetes Care. 28:1083-1091.

90. Heine, R.J., et al. 2005. Exenatide versus insulin glargine in patients with suboptimally controlled type 2 diabetes: a randomized trial. Ann. Intern. Med. 143:559-569.

91. Harder, H., Nielsen, L., Tu, D.T., and Astrup, A. 2004. The effect of liraglutide, a long-acting glucagon-like peptide 1 derivative, on glycemic control, body composition, and 24-h energy expenditure in patients with type 2 diabetes. Diabetes Care. 27:1915-1921.

92. Madsbad, S., Schmitz, O., Ranstam, J., Jakobsen, G., and Matthews, D.R. 2004. Improved glycemic control with no weight increase in patients with type 2 diabetes after once-daily treatment with the longacting glucagon-like peptide 1 analog liraglutide (NN2211): a 12-week, double-blind, randomized, controlled trial. Diabetes Care. 27:1335-1342.

93. Gedulin, B.R., et al. 2005. Dose-response for glycaemic and metabolic changes 28 days after single injection of long-acting release exenatide in diabetic fatty Zucker rats. Diabetologia. 48:1380-1385.

94. Mitani, H., Takimoto, M., Hughes, T.E., and Kimura, M. 2002. Dipeptidyl peptidase IV inhibition improves impaired glucose tolerance in high-fat diet-fed rats: study using a Fischer 344 rat substrain deficient in its enzyme activity. Jpn. J. Pharmacol. 88:442-450.

95. Marguet, D., et al. 2000. Enhanced insulin secretion and improved glucose tolerance in mice lacking CD26. Proc. Natl. Acad. Sci. U. S. A. 97:6874-6879.

96. Ahren, B., Holst, J.J., Martensson, H., and Balkan, B. 2000. Improved glucose tolerance and insulin secretion by inhibition of dipeptidyl peptidase IV in mice. Eur. J. Pharmacol. 404:239-245.

97. Pederson, R.A., et al. 1998. Improved glucose tolerance in Zucker fatty rats by oral administration of the dipeptidyl peptidase IV inhibitor isoleucine thiazolidide. Diabetes. 47:1253-1258.

98. Ahren, B., et al. 2004. Inhibition of dipeptidyl peptidase- 4 reduces glycemia, sustains insulin levels, and reduces glucagon levels in type 2 diabetes. J. Clin. Endocrinol. Metab. 89:2078-2084.

99. Ahren, B., et al. 2002. Inhibition of dipeptidyl peptidase IV improves metabolic control over a 4week study period in type 2 diabetes. Diabetes Care. 25:869-875.

100.Ahren, B., Holst, J.J., and Efendic, S. 2000. Antidiabetogenic action of cholecystokinin-8 in type 2 diabetes. J. Clin. Endocrinol. Metab. 85:1043-1048.

101.Boushey, R.P., et al. 2003. Hypoglycemia, defective islet glucagon secretion, but normal islet mass in mice with a disruption of the gastrin gene. Gastroenterology. 125:1164-1174.

102. Kuntz, E., Pinget, M., and Damge, P. 2004. Cholecystokinin octapeptide: a potential growth factor for pancreatic beta cells in diabetic rats. JOP. 5:464-475.

103. Rooman, I., Lardon, J., and Bouwens, L. 2002. Gastrin stimulates beta-cell neogenesis and increases islet mass from transdifferentiated but not from normal exocrine pancreas tissue. Diabetes. 51:686-690.

104. Rooman, I., and Bouwens, L. 2004. Combined gastrin and epidermal growth factor treatment induces islet regeneration and restores normoglycaemia in C57Bl6/J mice treated with alloxan. Diabetologia. 47:259-265. 
105.Suarez-Pinzon, W.L., Yan, Y., Power, R., Brand, S.J., and Rabinovitch, A. 2005. Combination therapy with epidermal growth factor and gastrin increases beta-cell mass and reverses hyperglycemia in diabetic NOD mice. Diabetes. 54:2596-2601.

106.Suarez-Pinzon, W.L., Lakey, J.R., Brand, S.J., and Rabinovitch, A. 2005. Combination therapy with epidermal growth factor and gastrin induces neogenesis of human islet beta-cells from pancreatic duct cells and an increase in functional beta-cell mass. J. Clin. Endocrinol. Metab. 90:3401-3409.

107. Druce, M.R., et al. 2005. Ghrelin increases food intake in obese as well as lean subjects. Int. J. Obes. (Lond.) 29:1130-1136.

108.Prado, C.L., Pugh-Bernard, A.E., Elghazi, L., SosaPineda, B., and Sussel, L. 2004. Ghrelin cells replace insulin-producing beta cells in two mouse models of pancreas development. Proc. Natl. Acad. Sci.U.S. A. 101:2924-2929.

109. Dezaki, K., et al. 2004. Endogenous ghrelin in pancreatic islets restricts insulin release by attenuating $\mathrm{Ca} 2+$ signaling in beta-cells: implication in the glycemic control in rodents. Diabetes. 53:3142-3151.

110.Sun, Y., Asnicar, M., Saha, P.K., Chan, L., and Smith, R.G. 2006. Ablation of ghrelin improves the diabetic but not obese phenotype of ob/ob mice. Cell Metab. 3:379-386.
111.Theander-Carrillo, C., et al. 2006. Ghrelin action in the brain controls adipocyte metabolism. J. Clin. Invest. 116:1983-1993. doi:10.1172/JCI25811.

112.Irako, T., et al. 2006. Ghrelin prevents development of diabetes at adult age in streptozotocin-treated newborn rats. Diabetologia. 49:1264-1273.

113. Besterman, H.S., et al. 1982. Gut hormone release after intestinal resection. Gut. 23:854-861.

114.Besterman, H.S., et al. 1983. Gut hormones in inflammatory bowel disease. Scand. J. Gastroenterol. 18:845-852.

115.Xiao, Q., Boushey, R.P., Cino, M., Drucker, D.J., and Brubaker, P.L. 2000. Circulating levels of glucagonlike peptide- 2 in human subjects with inflammatory bowel disease. Am. J. Physiol. 278:R1057-R1063.

116. Naslund, E., Backman, L., Holst, J.J., Theodorsson, E., and Hellstrom, P.M. 1998. Importance of small bowel peptides for the improved glucose metabolism 20 years after jejunoileal bypass for obesity. Obes. Surg. 8:253-260.

117. Le Roux, C.W., et al. 2006. Gut hormone profiles following bariatric surgery favor an anorectic state, facilitate weight loss, and improve metabolic parameters. Ann. Surg. 243:108-114.

118.Morinigo, R., et al. 2006. Glucagon-like peptide-1, peptide YY, hunger, and satiety after gastric bypass surgery in morbidly obese subjects. J. Clin. Endocrinol.
Metab. 91:1735-1740

119.Patti, M.E., et al. 2005. Severe hypoglycemia post-gastric bypass requiring partial pancreatectomy: evidence for inappropriate insulin secretion and pancreatic islet hyperplasia. Diabetologia. 4:2236-2240.

120.Service, G.J., et al. 2005. Hyperinsulinemic hypoglycemia with nesidioblastosis after gastric-bypass surgery. N. Engl. J. Med. 353:249-254.

121.Meier, J.J., Butler, A.E., Galasso, R., and Butler, P.C. 2006. Hyperinsulinemic hypoglycemia after gastric bypass surgery is not accompanied by islet hyperplasia or increased beta-cell turnover. Diabetes Care. 29:1554-1559.

122.Jackson, R.S., et al. 2003. Small-intestinal dysfunction accompanies the complex endocrinopathy of human proprotein convertase 1 deficiency. J. Clin. Invest. 112:1550-1560. doi:10.1172/JCI200318784.

123. Wang, J., et al. 2006. Mutant neurogenin-3 in congenital malabsorptive diarrhea. N. Engl. J. Med. 355:270-280

124.Grant, S.F., et al. 2006. Variant of transcription factor 7-like 2 (TCF7L2) gene confers risk of type 2 diabetes. Nat. Genet. 38:320-323.

125. Florez, J.C., et al. 2006. TCF7L2 polymorphisms and progression to diabetes in the Diabetes Prevention Program. N. Engl. J. Med. 355:241-250. 